\title{
Have Progression-Free Survival and Cancer-Specific Survival in Bladder Tumors Changed in Recent Decades?
}

\author{
Eva Mallén”, ${ }^{\mathrm{a}}$, Maria Jesus Gil ${ }^{\mathrm{b}}$, Pedro Gil ${ }^{\mathrm{b}}$, Jaume Pelegri Gabarro ${ }^{\mathrm{a}}$, Ingrid Guiote Partido ${ }^{\mathrm{a}}$
}

\begin{abstract}
Background: To find out whether, despite greater surgical experience and lower perioperative mortality, PFS (progression free survival) and CSS (cancer-specific survival) due to bladder tumors have undergone variations in the last 30 years and the attributable causes. An objective is also to determine which risk factors can influence the evolution of muscle invasive bladder cancer (MIBC).
\end{abstract}

Methods: A retrospective study of 599 patients who underwent radical cystectomy between 1975 and 2007. Firstly we performed a study of the conduct of all the studied variables throughout the nearly four decades studied. In order to determine which factors could predict progression and death due to bladder tumors a univariate and multivariate study was performed on the 563 patients who underwent radical cystectomy.

Results: No differences were observed in PFS nor CSS over the four periods studied. On the contrary if there has been a decrease in surgical complications. Only two variables retained independent prognostic value in multivariate analysis both in PFS and CSS; pathological organ confinement and lymph node involvement.

Conclusions: No significant differences were observed in progression free survival and in cancer- specific survival in patients who underwent cystectomy for bladder cancer over the four periods studied. Non organ confinement and lymph node involvement in the radical cystectomy specimen are the factors that maintain independent prognostic value for cancer-specific survival and progression-free survival in the multi-variate analysis.

Keywords: Radical cystectomy; Invasive bladder cancer; Survival

\footnotetext{
Manuscript accepted for publication May 27, 2013

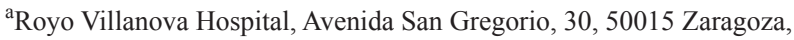
Spain

${ }^{\mathrm{b}}$ Miguel Servet University Hospital, Avenida Isabel La Catolica 1-3, 50009 Zaragoza, Spain

${ }^{\mathrm{c}}$ Corresponding author: Eva Mallén, Paseo $\mathrm{M}^{\mathrm{a}}$ Agustin $\mathrm{n}^{\mathrm{o}} 1 ; 5^{\circ}$ centro,

50004 - Zaragoza, Spain. Email: evamallen@hotmail.com
}

doi: http://dx.doi.org/10.4021/wjnu92w

\section{Introduction}

Bladder cancer is the seventh most common cancer in the world and the fifth most common in men in developed countries. It accounts for $3 \%$ of all tumors ( $4.4 \%$ in men and 1.6 in women) [1-3]. It is more common from the age of sixty onwards.

The highest incidence for both sexes is found in Europe, the US and Australia [4]. In Europe bladder cancer ranked fourth in incidence in men and seventh in mortality, with a world-adjusted incidence of 16.7/100,000 in habitants in men and 3.2 in women. The ratio of bladder cancer in men to women is $3.8: 1[2,3]$.

Spain is among the countries with the highest incidence of bladder cancer. In 2008 it ranked second worldwide, after Israel, and it is the country with the highest incidence in Europe [2]. Spain has an estimated age and European population-adjusted rate of 27.7/100,000 inhabitants [3] and this figure is undergoing a gradual upward trend.

With regard to mortality, in Europe Spain ranks very highly in bladder cancer mortality, which makes it a major health problem. In 2008 it was the fourth leading cause of cancer deaths in men in Spain [5].

But the most striking aspect can be seen in data from the National Epidemiology Centre [5], which shows the pattern that mortality has followed over time in Spain. Unlike the case of prostate cancer, there has been no fall in mortality as treatment has become more aggressive.

\section{Objective}

To find out whether despite greater surgical experience and lower perioperative mortality PFS and CSS due to bladder tumors have undergone variations in the last 30 years and the attributable causes. An objective was also to determine which risk factors can influence the evolution of muscle invasive bladder cancer (MIBC).

\section{Material and Methods}

This was a retrospective study of all patients who underwent 
Table 1. Variables Studied

\begin{tabular}{|c|c|c|}
\hline Pre-Cystectomy Variables & Peri-Cystectomy Variables & Post-Cystectomy Variables \\
\hline Gender & Transfusion & Hospital stay \\
\hline Age & Type of catheterisation & Follow-up \\
\hline Smoker & Ureteral reimplantation & Adjuvant CT \\
\hline Alcohol & Pathological stage (pT) & Major perioperative complications \\
\hline Risk occupation & Tumor grade & Minor perioperative complications \\
\hline Living environment & Lymph node involvement (pN) & Late-onset complications \\
\hline Comorbidity & Presence of CIS & Tumor recurrence in UUT \\
\hline Clinical presentation & P53 & \\
\hline Clinical stage of TURBT & Anatomical pathology Terminal ureter & \\
\hline History of SBC & Ureterectomy & \\
\hline History of UC in UUT & Anatomical pathology type & \\
\hline Neoadjuvant CT & Organ confinement & \\
\hline
\end{tabular}

TURBT: Transurethral resection of bladder tumour; SBC: Superficial bladder cancer; UC: Urothelial carcinoma; UUT: Upper urinary tract; CT: Chemotherapy; BC: Bladder cancer.

Table 2. Major Perioperative Complications, $N=563$

Type

$\mathrm{N}^{0}$ pacientes(\% respecto a $\left.\mathrm{N}=\mathbf{5 6 3}\right)$

\begin{tabular}{|c|c|c|c|}
\hline \multicolumn{2}{|c|}{ Early reoperation (bleeding, peritonitis, occlusion) } & 12 & $(2.1 \%)$ \\
\hline \multirow[t]{2}{*}{ Surgical } & Rectal injury & 5 & $(2.3 \%)$ \\
\hline & Evisceration & 8 & \\
\hline \multirow[t]{2}{*}{ Fistulas (with action) } & Intestinal leakage & 11 & $(2.1 \%)$ \\
\hline & Enteroneovesical fistula & 1 & \\
\hline Multi-organ failure & & 2 & $(0.3 \%)$ \\
\hline \multirow[t]{2}{*}{ Infectious } & Sepsis & 9 & $(1.7 \%)$ \\
\hline & Pseudomembranous colitis & 1 & \\
\hline PT & & 20 & $(3 \%)$ \\
\hline \multirow[t]{2}{*}{ Cardiological } & Acute MI & 2 & $(1.2 \%)$ \\
\hline & Acute pulmonary edema & 5 & \\
\hline Neurological & CVA & 1 & $(0.1 \%)$ \\
\hline \multirow[t]{2}{*}{ Respiratory } & Respiratory failure & 2 & $(0.5 \%)$ \\
\hline & Bronchoaspiration & 1 & \\
\hline Digestive & Liver failure & 3 & $(0.5 \%)$ \\
\hline Perioperative mortality & & 36 & $(6.4 \%)$ \\
\hline
\end{tabular}

Major perioperative complications (<30 days). 
Table 3. Minor Perioperative Complications (<30 Days)

\begin{tabular}{lc}
\hline Type & $\mathbf{N}^{\mathbf{0}}$ patients (\% of N = 563) \\
\hline Prolonged ileus & $47(8.3 \%)$ \\
Abscess (with action) & $11(1.9 \%)$ \\
Infected wound & $26(4.6 \%)$ \\
Urinary leak (with action) & $15(2.6 \%)$ \\
UTI with repercussion, pyelonephritis & $10(1.7 \%)$ \\
DVT & $5(0.8 \%)$ \\
Cardiac arrhythmia & $1(0.1 \%)$ \\
Pneumonia & $26(4, .6 \%)$ \\
Metabolic acidosis & $9(1.5 \%)$ \\
Upper GI bleeding & $14(2.4 \%)$ \\
Cholecystitis & $1(0.1 \%)$ \\
\hline
\end{tabular}

radical cystoprostatectomy for bladder cancer at Hospital Universitario Miguel Servet in Saragossa between 1975 and 2007. The study population consisted of the 599 patients who underwent radical cystectomy. Thirty-six patients were eliminated from the study due to missing data. Analysis was therefore performed on 563 patients.

"FileMaker Pro 11.0, version 11.0 v2" (FileMaker Inc ${ }^{\circ}$ ) was used as the database software and "PASW Statistics 18, version 18.0.0" $\left(\mathrm{IBM}^{\circ}\right)$ was used for the statistics software.

Before studying the different variables, we examined their normality using routine goodness-of-fit tests by Kolmogorov-Smirnov and Shapiro-Wilk. Depending on the normal or non-normal behaviour of the variables, their mean or median was used to express different characteristics. For inter-variable comparison, we used the routine significance of $\mathrm{P}<0.05$.

In the univariate analysis, for inter-variable comparison parametric tests were used when the variable was normal (usually the chi-square test for between categorical variables), and nonparametric tests were used when the variable

Table 4. Late-Onset Complications, $N=563$

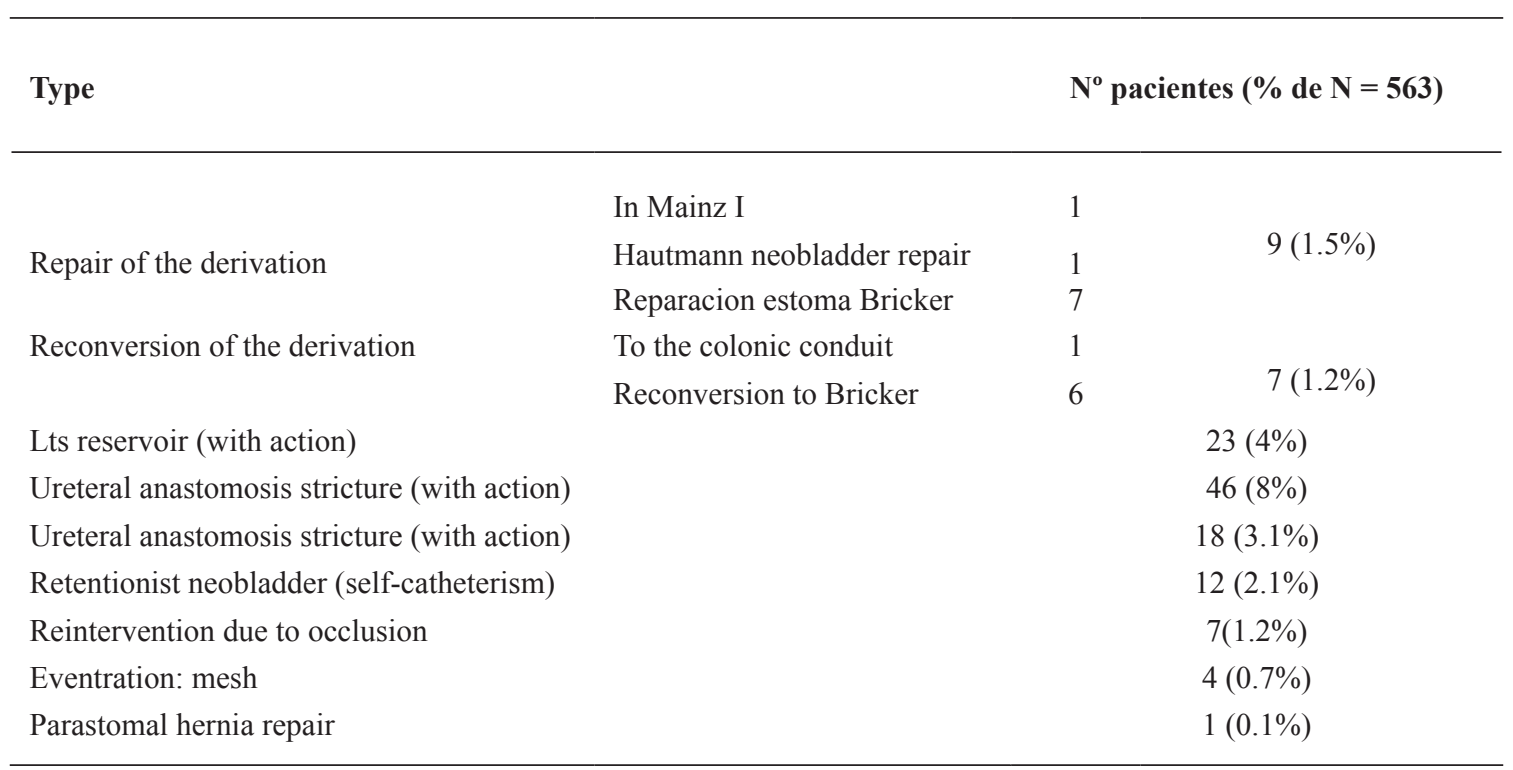




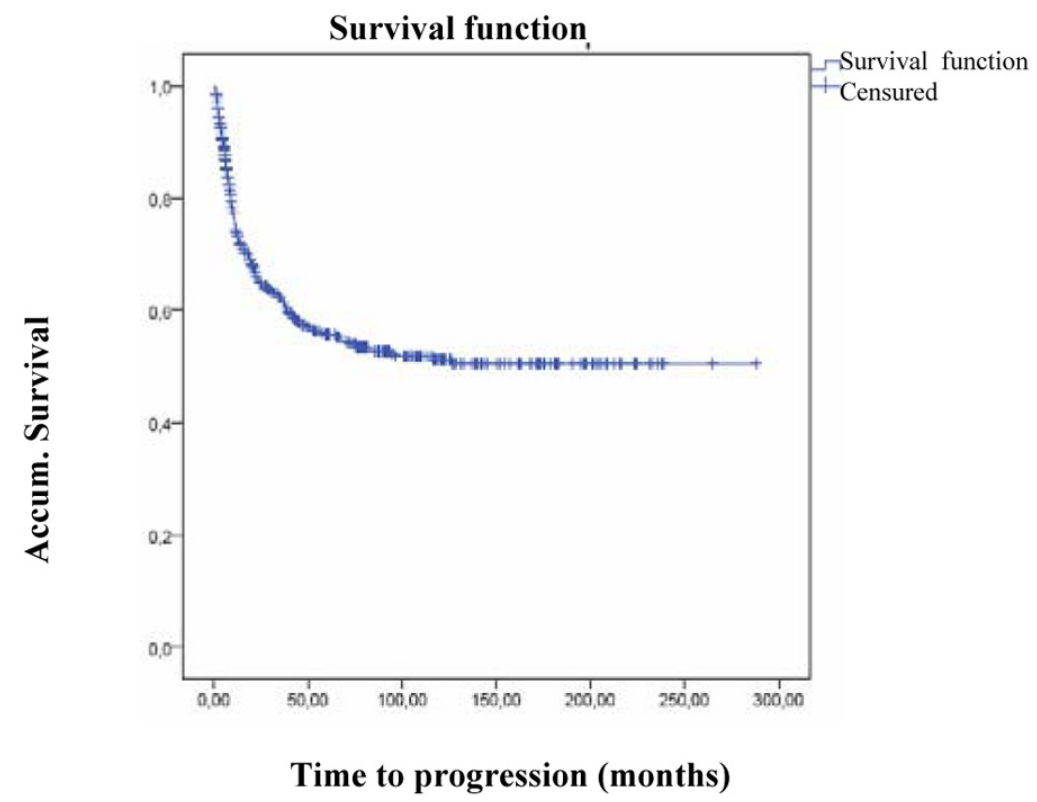

Figure 1. PFS in $n=563$.

was non-normal (usually the Kruskal-Wallis test between categorical and quantitative variables). The Kaplan-Meier test (or Mantel-Haensz) was used for the univariate comparison of survival curves.

For multivariate analysis, to compare the independent effect of each variable on a categorical survival outcome variable, we used the Cox regression method (proportional hazards model). In the multivariate analysis we used variables that had retained significance or close significance, in the univariate analysis. We used the "forward stepwise" method or "likelihood ratio" to enter the different variables in the final equation [6].

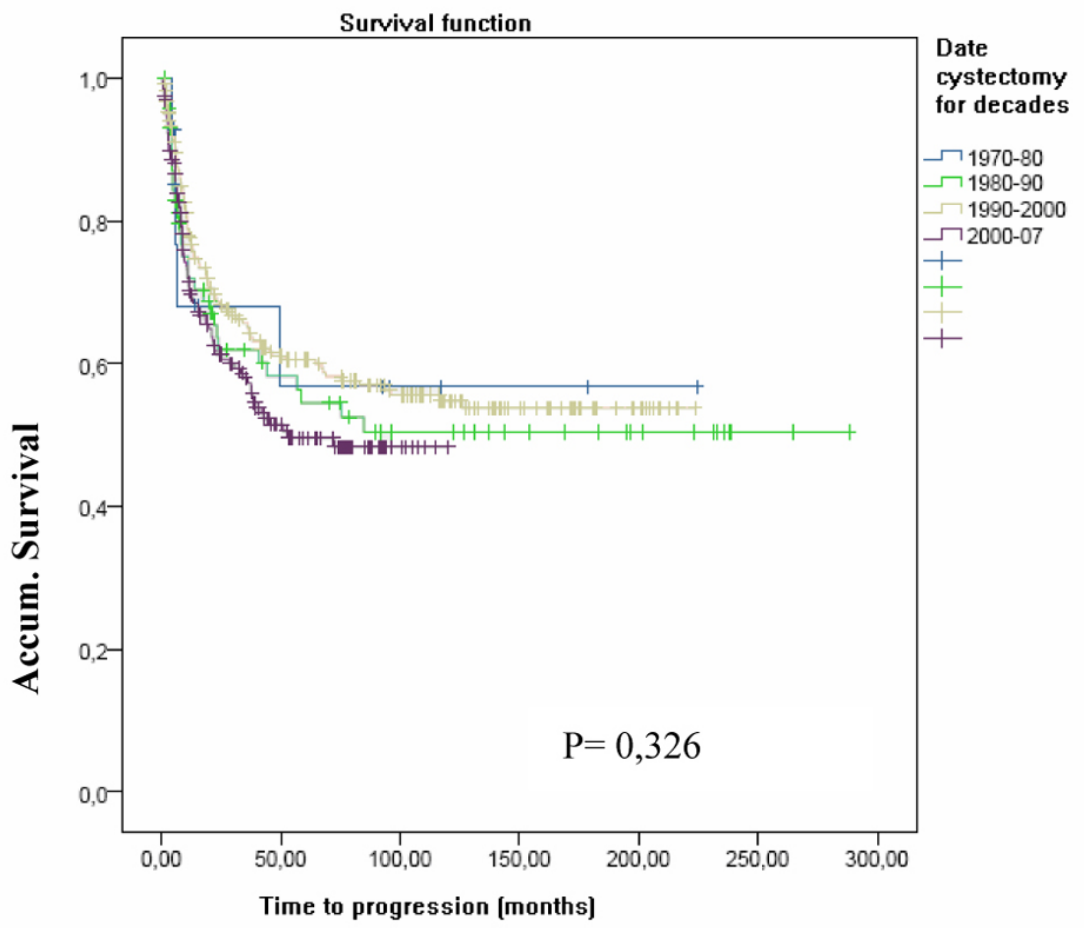

Figure 2. FPS in the four decades studied. 
Table 5. PFS Predictive Model

\begin{tabular}{|c|c|c|c|c|c|c|c|c|}
\hline \multirow{2}{*}{ Variable } & \multirow{2}{*}{ B } & \multirow{2}{*}{ SE } & \multirow{2}{*}{ Wald } & \multirow{2}{*}{ GI } & \multirow{2}{*}{$\mathbf{P}$} & \multirow{2}{*}{ O.R } & \multicolumn{2}{|c|}{ 95\% IC para Exp (B) } \\
\hline & & & & & & & Inferior & Superior \\
\hline Pathological organ confinement & 1.077 & 0.283 & 14.445 & 1 & 0.000 & 2.936 & 1.685 & 5.117 \\
\hline Nodal involvement & 0.861 & 0.214 & 16.219 & 1 & 0.000 & 2.365 & 1.556 & 3.595 \\
\hline
\end{tabular}

\section{Results}

Cystectomy was indicated for muscle-invasive bladder cancer (MIBC) in 493 patients (379 patients were initially diagnosed with "de novo" MIBC and 114 were diagnosed following progression of superficial bladder cancer). In the remaining 70 patients, the indication for cystectomy was superficial bladder cancer. In these 70 cases, 33 underwent cystectomy for multifocal recurrence of SBC (superficial bladder cancer) 36 for recurrent high-grade tumours and in one case the reason for cystectomy were not specified.

We divided the 30-plus years that the study covered into four time periods corresponding almost exactly to four decades. The variables investigated in patients treated with cystectomy in the period of study were grouped into: pre-, peri- and post-cystectomy variables, as shown in Table 1 below (Variables studied). Besides descriptive study conducted a comparative study of all variables over the decades. The sample of 563 patients who underwent cystectomy was followed for a median of 37.8 months.

At the time of cystectomy the median age was 65.3 years (IQR 13.1) (In the analysis by decades it can be seen that the patients were progressively older, with statistically significant differences). Comparing median ages, there was a gradual increase in the median age of patients at the time of surgery, ranging from 59.4 years (IQR 7.62) in the 1970s to a median of 68 years (IQR 14.05) in the final time period (2000 - 2007) $(\mathrm{P}=0.00)$.

\section{Survival funtion}

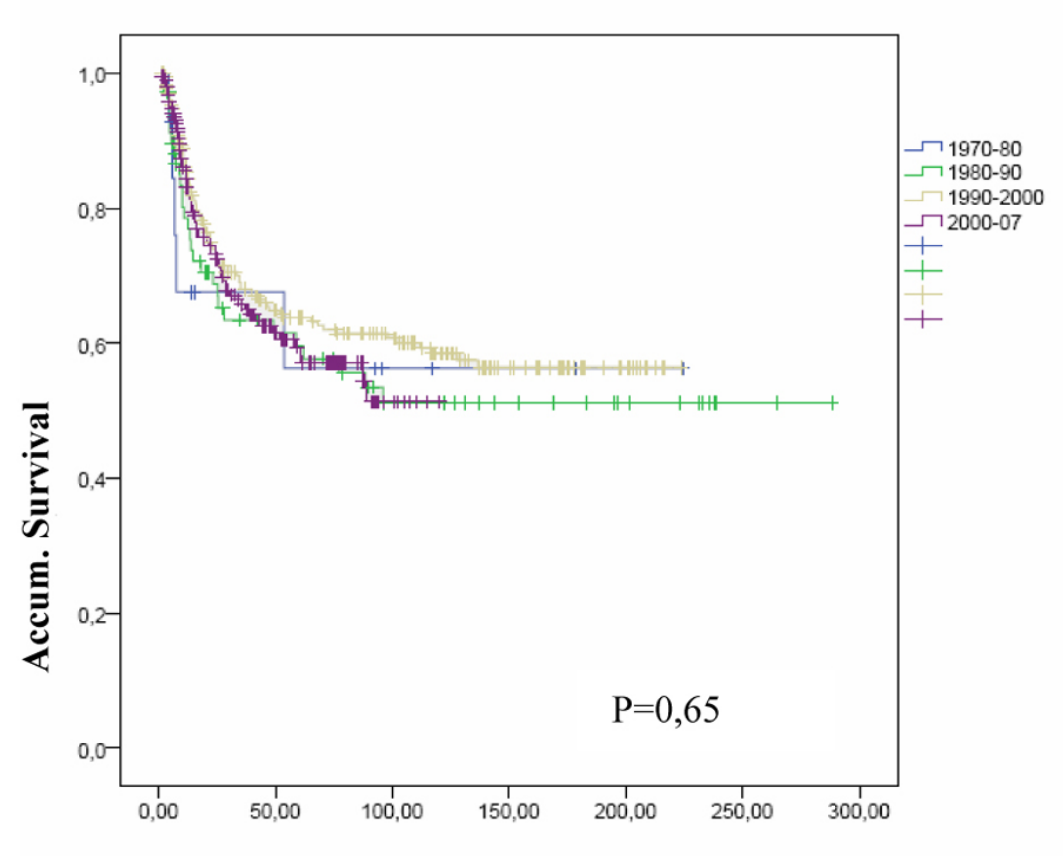

Follow up

Figure 3. CSS in the tour decades studied. 


\begin{tabular}{|c|c|c|c|c|c|c|c|c|}
\hline \multirow{2}{*}{ Variable } & \multirow{2}{*}{ B } & \multirow{2}{*}{ SE } & \multirow{2}{*}{ Wald } & \multirow{2}{*}{ gl } & \multirow{2}{*}{$\mathbf{P}$} & \multirow{2}{*}{ O.R } & \multicolumn{2}{|c|}{$95 \%$ CI for $\operatorname{Exp}(B)$} \\
\hline & & & & & & & Inferior & Superior \\
\hline Pathological organ confinement & 0.906 & 0.233 & 15.097 & 1 & 0.000 & 2.475 & 1.567 & 3.909 \\
\hline Nodal involvement & 0.849 & 0.192 & 19.466 & 1 & 0.000 & 2.336 & 1.603 & 3.406 \\
\hline
\end{tabular}

Although improvements in surgical technique such as the use of bipolar vessel sealing or mechanical sutures have contributed towards shorter surgical times and thereby significantly decrease transfused units and hospital stay. The surgical technique itself has not undergone significant changes over the decades. Ileobturatriz lymphadenectomy was performed mostly in all periods ( $84 \%$ of patients), but with a significant increase in the number of continent urinary diversions over the decades.

During follow up complications appeared which were divided into major, minor and late-onset according to importance and time of onset as rated by Lowrance [7]. In the study overall major perioperative complications occurred in $19.9 \%$ of patients, in $13.3 \%$ minor perioperative complications and some type of late-onset complication occurred in $26 \%$ of patients (Table 2), (Major perioperative complications), (Table 3), (Minor perioperative complications), (Table 4), (Late-onset complications).

In the analysis for decades, there is a significant decrease in major complications ( $\mathrm{P}=0.003$ ), from $33 \%$ in the first decade to $12 \%$ in recent years. As perioperative mortality refers to significant differences with a decrease in the same $22 \%$ of the first decade of $5 \%$ in recent years (figure and table not shown).

Median follow up was 37.8 months (IQR 83.4). Up to do this study, patients were followed up in our department with a first visit to 1.5 months of surgery and then every 6 months. On occasion, motivated patient clinic review was in a shorter period.

According to results of probabilities of progression and death (data not shown) we carried out a visitation according risk groups.

In 219 patients from the total series $(38.9 \%)$, "progression" phenomenon occurred, for example, there was urothelial disease recurrence following radical cystectomy. We classified recurrence as: local, regional lymph node and distant. In patients who progressed, the predominant type of progression was distant metastasis in $63 \%$ of cases.

The mean PFS (progression-free survival) in the 563 patients was 157 (144.2 - 169.9) months (the median could not be calculated), (Fig. 1), (PFS in $\mathrm{n}=563$ )

In patients who progressed, $\mathrm{n}=219(38.9 \%)$ median pro- gression-free survival was 9.7 months (CI 95\% 8.3 - 11.1).

Throughout the decades of the study there were no statistically significant differences neither in the progression phenomenon nor in PFS. Patients who underwent cystectomy progressed in a similar manner in the decades of the study as can be seen in the Figure 2 (FPS in the four decades studied).

Pathological organ confinement, lymph node involvement, tumor grade, terminal ureter involvement and the administration of adjuvant chemotherapy were the variables that were significantly associated to lower progression-free survival in the univariate analysis.

In the multivariate analysis we entered the significant variables detected in the univariate analysis and found that pathological organ confinement and lymph node involvement were independent variables significantly associated with PFS (Table 5), (PFS predictive model).

For the total patients $(\mathrm{n}=563)$, mean CSS (cancer-specific survival) was 169 months $(156.2$ - 182.3) from the cystectomy date.

Similarly to PFS, that almost all events (deaths from BC) occurred in the first three years of follow up. In fact, by the end of the third year of follow up, $81 \%$ of the events had already occurred. There was an $83 \%$ probability of survival for the first year, falling to $61 \%$ at the end of the fifth year, with little further change at the end of the tenth year $(55 \%)$.

Over the decades of the study no differences were achieved with respect to CSS (Fig. 3), (CSS in the tour decades studied, $\mathrm{P}=0.65$ ).

As shown in this Table 6 (CSS predictive model), only two variables retained an independent prognostic value for CSS, as was the case for PFS: pathological organ confinement and lymph node involvement.

\section{Discussion}

One of the main justifications for our study is the high incidence and mortality rates of bladder cancer in our country, Spain. Rates, together with the over-aging of the population, suggest that these levels will persist.

In our analysis there is no difference in the percentage 
Table 7. Mortality and Morbidity in Different Series

\begin{tabular}{lll}
\hline \multicolumn{2}{c}{ Perioperative mortality and \% of complications in radical cystectomy } \\
\hline Referentes & Mortality & Morbidity \\
\hline Lowrance et al [7] & $1.7 \%$ & $41 \%$ \\
Skinner et al [10] & $2.4 \%$ & $28 \%$ \\
Lee et al [11] & $1.6 \%$ & $45 \%$ \\
Stimson [13] & $2.1 \%($ days $)$ y $6.9 \%(90 \mathrm{~d})$ & $26 \%$ \\
Chahal [14] & $8.6 \%$ & $25.6 \%$ \\
Frazier et al [21] & $2.5 \%$ & $31.9 \%$ \\
Freiha [22] & $3.3 \%$ & $41 \%$ \\
Stein et al [23] & $2.5 \%$ & $28 \%$ \\
Hautmann et al [24] & $3.0 \%$ & $39 \%$ \\
\hline
\end{tabular}

of patients with organ confined tumors over the decades. Localized disease remained stable, with no observed increase or decrease of the same in recent years. Nor was there a decline in extravesical disease (pT3 and pT4) or lymph node involvement. Lymph node involvement was found in $26 \%$ of patients at diagnosis, in accordance with the percentages of other series (between 13\% and 33.1\% [1,8]).

One study of clinical and pathological variables by decades, similar to our own, was undertaken was Monzo [9] et al. The increase in extravesical disease (pT3-4, pN0) and decrease in intravesical disease (pT0-2) differ to our data. Another difference was in the case of lymph node involvement $(\mathrm{pN}+)$ which remained stable. In our case we observed an increase in lymph node involvement over the decades, although this was not significant $(\mathrm{P}=0.250)$. At the same time this group highlights a significant increase in the overall use of adjuvant chemotherapy ( $\mathrm{P}=0.006)$; this could be justified by the increase observed in extravesical disease.

The range of complications varies according to groups from $28[10,11]$ to $45 \%$ [12]. Following the scheme of Lowrance et al [7] in our series we found major perioperative complications to be $19.9 \%$, minor complications to be $13.2 \%$ and late-onset complications to be $26.1 \%$. These percentages are in accordance with the revised series as can be seen in Table 7 (Mortality and morbidity in different series). Both, older and late complications, have fallen over the decades significantly

There is no universality in perioperative morbidity classification criteria. In our case we have used the classification of Lowrance et al [7], however diversity does exist in the use of the classifications. Many surgical specialists use Clavien classification [13], dividing into 5 degrees according on severity, which makes it tremendously difficult to make a comparison of the proportion of complications between the series.

On analysis we find perioperative mortality to be $6.4 \%$, a slightly elevated figure, but similar mortality data was described in recent literature such as of Stimson [14] of $6.9 \%$ in the 90 day period post-cystectomy or Chahal [15] with 8.6\% within the same period. In analysis by decades we observe a significant decrease from $22 \%$ in the 1970 s to $5 \%$ in recent years. An improvement observed in the majority of series, such as those analysed by authors such as Rosario [16], who in one study at the beginning of the 2000s highlighted a marked decrease in morbidity and mortality highlighting, or Glantz [17], with a mortality of $20 \%$ in the decade of the $1960 \mathrm{~s}$, and others with values between $2-3 \%$ in more recent times [18-20] as is reflected in Table 7 (Mortality and morbidity in different series).

In the study of PFS and CSS over the decades we did not observe significant differences in the four periods. This fact should give us pause, as despite the great advances in surgical techniques we improved in the number of complications but, we have not reduced bladder cancer mortality.

From the fact that over the four decades studied the diagnosis of more organ confined tumors was not achieved, we can deduce that early diagnosis is lacking in bladder cancer. In this sense, there have been many proposals, from early diagnosis of this tumor or the search for a gene or protein which discriminates those tumors with a better prognosis 
from those with a poor outcome. A clear example is ezrin protein expression in superficial bladder tumors as a possible predictor of disease progression [21]. Or the WWOX protein, the loss of the expression of this protein could be useful in the prediction of bladder tumor progression [22].

From other fields such as molecular biology, Rioja Zuazu $[23,24]$ demonstrates how the expression of steroids and SXR xenobiotics are expressed in normal and cancerous bladder, but this expression correlates with prognostic factors influencing survival, especially in patients of stages pT3-T4N0.

\section{Conclusions}

No significant increase in the percentage of pathological organ confined tumors was observed in patients who underwent cystectomies throughout the 30 years of the study.

No significant differences in PFS and CSS were observed in patients who underwent cystectomies for bladder cancer over the four periods studied.

Non organ confinement and lymph node involvement in the radical cystectomy specimen are the factors that maintain independent prognostic value for cancer-specific survival and progression-free survival in the multivariate analysis.

\section{References}

1. Monzo Gardiner JI, Herranz Amo F, Diez Cordero JM, Cabello Benavente R, Silmi Moyano A, Hernandez Fernandez C. [Prognostic factors for survival in patients with transitional bladder cancer treated with radical cystectomy]. Actas Urol Esp. 2009;33(3):249-257.

2. Asociacion Espanola contra el Cancer. http://www.todocancer.com.

3. Globocan 2008. International Agency for research on Cancer. Accessed January 2011. Available at www.globocan.iarc.fr.

4. Parkin DM, Whelan SL, Ferlay J, Teppo L and Thomas DB (eds) (2003). Cancer incidence in five continents, Vol VIII, IARC Scientific Publications No. 155, Lyon, UARC.

5. Centro Nacional de Epidemiologia. Area de Epidemiologia Ambiental y Cancer. Mortalidad por Cancer en Espana. Consulted 2011. Available at: http://cne.isciii.es.

6. Domenech JM, Sarria A. "Modelos de regresion con datos de supervivencia: modelo de riesgos proporcionales de Cox". In: Analisis Multivariante en Ciencias de la Salud. Modelos de Regresion. Unidad Didactica 16. Ed. SIGNO, Barcelona.

7. Lowrance WT, Rumohr JA, Chang SS, Clark PE, Smith JA, Jr., Cookson MS. Contemporary open radical cystectomy: analysis of perioperative outcomes. J Urol. 2008;179(4):1313-1318; discussion 1318.

8. Stein JP, Lieskovsky G, Cote R, Groshen S, Feng AC,
Boyd S, Skinner E, et al. Radical cystectomy in the treatment of invasive bladder cancer: long-term results in 1,054 patients. J Clin Oncol. 2001;19(3):666-675.

9. Monzo Gardiner JI, Herranz Amo F, Cabello Benavente R, Diez Cordero R, Lopez Diez I, Tabares Jimenez J, Molina Escudero R, et al. [Response to adjuvant chemotherapy after radical cystectomy in patients with infiltrative bladder: Analysis of 397 cases]. Arch Esp Urol. 2009;62(4):275-282.

10. Skinner DG, Tift JP, Kaufman JJ. High dose, short course preoperative radiation therapy and immediate single stage radical cystectomy with pelvic node dissection in the management of bladder cancer. J Urol. 1982;127(4):671-674.

11. Stein JP. Lymphadenectomy in bladder cancer: how high is "high enough"? Urol Oncol. 2006;24(4):349-355.

12. Lee CT, Dunn RL, Chen BT, Joshi DP, Sheffield J, Montie JE. Impact of body mass index on radical cystectomy. J Urol. 2004;172(4 Pt 1):1281-1285.

13. Dindo D, Demartines N, Clavien PA. Classification of surgical complications: a new proposal with evaluation in a cohort of 6336 patients and results of a survey. Ann Surg. 2004;240(2):205-213.

14. Stimson CJ, Chang SS, Barocas DA, Humphrey JE, Patel SG, Clark PE, Smith JA, Jr., et al. Early and late perioperative outcomes following radical cystectomy: 90-day readmissions, morbidity and mortality in a contemporary series. J Urol. 2010;184(4):1296-1300.

15. Chahal R, Sundaram SK, Iddenden R, Forman DF, Weston PM, Harrison SC. A study of the morbidity, mortality and long-term survival following radical cystectomy and radical radiotherapy in the treatment of invasive bladder cancer in Yorkshire. Eur Urol. 2003;43(3):246257.

16. Rosario DJ, Becker M, Anderson JB. The changing pattern of mortality and morbidity from radical cystectomy. BJU Int. 2000;85(4):427-430.

17. Glantz GM. Cystectomy and urinary diversion. J Urol. 1966;96(5):714-717.

18. Frazier HA, Robertson JE, Paulson DF. Complications of radical cystectomy and urinary diversion: a retrospective review of 675 cases in 2 decades. J Urol. 1992;148(5):1401-1405.

19. Hautmann RE, de Petriconi R, Gottfried HW, Kleinschmidt K, Mattes R, Paiss T. The ileal neobladder: complications and functional results in 363 patients after 11 years of followup. J Urol. 1999;161(2):422-427; discussion 427-428.

20. Freiha F, Reese J, Torti FM. A randomized trial of radical cystectomy versus radical cystectomy plus cisplatin, vinblastine and methotrexate chemotherapy for muscle invasive bladder cancer. J Urol. 1996;155(2):495-499; discussion 499-500.

21. Palou J, Algaba F, Vera I, Rodriguez O, Villavicencio 
H, Sanchez-Carbayo M. Protein expression patterns of ezrin are predictors of progression in T1G3 bladder tumours treated with nonmaintenance bacillus CalmetteGuerin. Eur Urol. 2009;56(5):829-836.

22. Ramos D, Abba M, Lopez-Guerrero JA, Rubio J, Solsona E, Almenar S, Llombart-Bosch A, et al. Low levels of WWOX protein immunoexpression correlate with tumour grade and a less favourable outcome in patients with urinary bladder tumours. Histopathology. 2008;52(7):831-839.

23. Rioja J, Bandres E, Rosell D, Rincon A, Zudaire J, Gil MJ, Rioja LA, Garcia J, Berian JM. Expresion del re- ceptor de esteroides y xenobioticos (SXR) y del gen de multirresistencia drogas (MDR1) y de los polimorfismos de las enzimas GSTs, SULTs y CYP en tumores vesicales profundos, analisis de su expresion y correlación con otros factores pronósticos. Actas Esp Urol. 2007;31:1106-1117.

24. Rioja J, Bandres E, Rosell Costa D, Rincon A, Lopez I, Zudaire Bergera JJ, Garcia Foncillas J, et al. Association of steroid and xenobiotic receptor (SXR) and multidrug resistance 1 (MDR1) gene expression with survival among patients with invasive bladder carcinoma. BJU Int. 2011;107(11):1833-1838. 